\title{
Pseudo-pseudo Meigs' syndrome: a rare presentation of systemic lupus erythematosus
}

\author{
G. Tansir, P. Kumar, A. Pius, S.K. Sunny, M. Soneja \\ Department of Medicine, All India Institute of Medical Sciences, New Delhi and Patna, India
}

\section{SUMMARY}

Systemic lupus erythematosus (SLE) is a chronic inflammatory multisystem autoimmune disease. Ascites when associated with pleural effusion and raised CA-125 levels in SLE patient, is known as pseudo-pseudo Meigs' syndrome (PPMS). This is the case of a 22-year-old lady who presented with complaints of abdominal distension for one month and had a history of spontaneous abortion in the past. Abdominal imaging did not reveal any tumor and after extensive workup a diagnosis of PPMS was made. She was successfully treated with steroids, hydroxychloroquine and cyclophosphamide.

Key words: Serositis; lupus nephritis; antiphospholipid syndrome; splenic infarct; thrombocytopenia.

Reumatismo, 2019; 71 (2): 108-112

\section{INTRODUCTION}

Cerositis is seen in approximately $16 \%$ $\checkmark$ of lupus patients in the form of pleuritis and/or pericarditis. Peritoneal serositis with ascites (also known as lupus peritonitis) is rarely seen in systemic lupus erythematosus (SLE), and ascites as initial manifestation of lupus is even rarer $(1,2)$. Ascites in SLE is secondary to nephrotic syndrome, constrictive pericarditis, protein losing enteropathy and rarely due to lupus flare.

Cancer antigen 125 (CA-125) is a widely used tumor marker for screening of adnexal malignancies. Tjalma in 2005 described a case of SLE with ascites, pleural effusion and raised CA-125 levels (3). Schmitt et al. presented a similar case and named this entity as pseudo-pseudo Meigs' syndrome (PPMS) (4). Since then only 7 more cases have been reported so far (5-10). We present a case of PPMS in a previously undiagnosed SLE patient with review of literature on the same.

\section{CASE REPORT}

A 22-year-old lady presented with complaints of gradually progressive, pain- less abdominal distension for the past one month. There was no history of fever, weight loss, oliguria, feet edema, jaundice, breathlessness, joint pain, rash or oral ulcers. She had a spontaneous abortion at 24 weeks of gestation in the past. On examination, she had pallor and her vital parameters were normal. Her abdomen was grossly distended and bilateral breath sounds were reduced. The remaining systemic examination was essentially normal.

Blood investigation was suggestive of bicytopenia (hemoglobin- $7.1 \mathrm{gm} / \mathrm{dL}$ ), with platelet count- $(30,000 / \mathrm{cu} \mathrm{mm})$, total leucocyte count - 6800/cu mm and MCV- 82 fL. Peripheral smear showed microcytic hypochromic anemia and iron studies revealed low iron stores with mildly raised ferritin levels ( $239 \mathrm{ng} / \mathrm{mL})$. Direct and indirect Coombs tests were positive, however, serum lactate dehydrogenase (LDH), haptoglobin and bilirubin levels were normal. Erythrocyte sedimentation rate (ESR) was $60 \mathrm{~mm} / \mathrm{hr}$ and C-reactive protein (CRP) level was $44.8 \mathrm{mg} / \mathrm{L}$ (normal $<6 \mathrm{mg} / \mathrm{L}$ ). She had low serum albumin levels $(1.5 \mathrm{gm} /$ $\mathrm{dL}$ ) and other parameters of liver function test were normal. CA-125 level was done in view of massive ascites and was signifi- 
cantly raised to $2025 \mathrm{U} / \mathrm{mL}$ (normal: 0-35). Renal and thyroid function tests were normal but urine examination showed proteinuria and $24 \mathrm{~h}$ urinary protein was $1100 \mathrm{mg} /$ day.

Ascitic tap was done, which showed 75 cells (all lymphocytes), glucose- $42 \mathrm{mg} /$ $\mathrm{dL}$, albumin $1.3 \mathrm{gm} / \mathrm{dL}$ and a SAAG (serum ascites albumin gradient) of $<1.1$. Ascitic fluid evaluation for tuberculosis, bacterial, fungal and malignant pathologies were negative.

Chest $\mathrm{X}$ ray showed blunting of bilateral costophrenic angles. Ultrasound abdomen and pelvis revealed massive ascites and bilateral pleural effusion with normal spleno-portal axis. Echocardiography showed minimal pericardial effusion with normal ventricular function. Contrast-enhanced computed tomography (CECT) of chest, abdomen and pelvis showed gross ascites, bilateral pleural effusion (right>left) and mild pericardial effusion with multiple wedge shaped splenic infarcts (Figure 1AC). There was no adnexal mass on pelvic imaging and no thrombus was noted in the intra-abdominal vessels. Since the patient had polyserositis, thrombocytopenia, splenic infarcts and a history of spontaneous abortion, an autoimmune workup was done. Immunofluorescent antinuclear antibody (ANA) test showed homogenous pattern with a titer of 1:320. Anti double stranded DNA antibody (ds DNA) level was markedly elevated $(939 \mathrm{IU} / \mathrm{mL})$. Complement levels were low, C3 level-29 mg/ dL (normal: 84-168) and C4 level- $6.8 \mathrm{mg} /$ dL (normal: 13-44 mg/dL). Antiphospholipid antibodies (aPL) test showed elevated levels of IgM anti-beta2 glycoprotein and anti-cardiolipin antibodies. A renal biopsy done in view of significant proteinuria, revealed class II lupus nephritis.

A diagnosis of PPMS, secondary immune thrombocytopenic purpura (ITP), class II lupus nephritis, secondary anti-phospholipid syndrome (APS) and splenic infarcts with a SLEDAI score of 13 (severe flare) was made.

She was given intravenous methylprednisolone pulse ( $1 \mathrm{gm}$ daily for 3 days), followed by $1 \mathrm{mg} / \mathrm{kg}$ of oral prednisolone.
Oral hydroxychloroquine, calcium and vitamin D supplementation was also added. After steroid therapy, the platelet count improved considerably and normalized within next 10 days. Pleural effusion and proteinuria also resolved in two weeks but there was no improvement in ascites. A repeat ascitic tap done after three weeks of steroid therapy again showed low SAAG ascites, suggesting ongoing disease activity. Since there was no significant improvement in ascites we decided to give an ad-
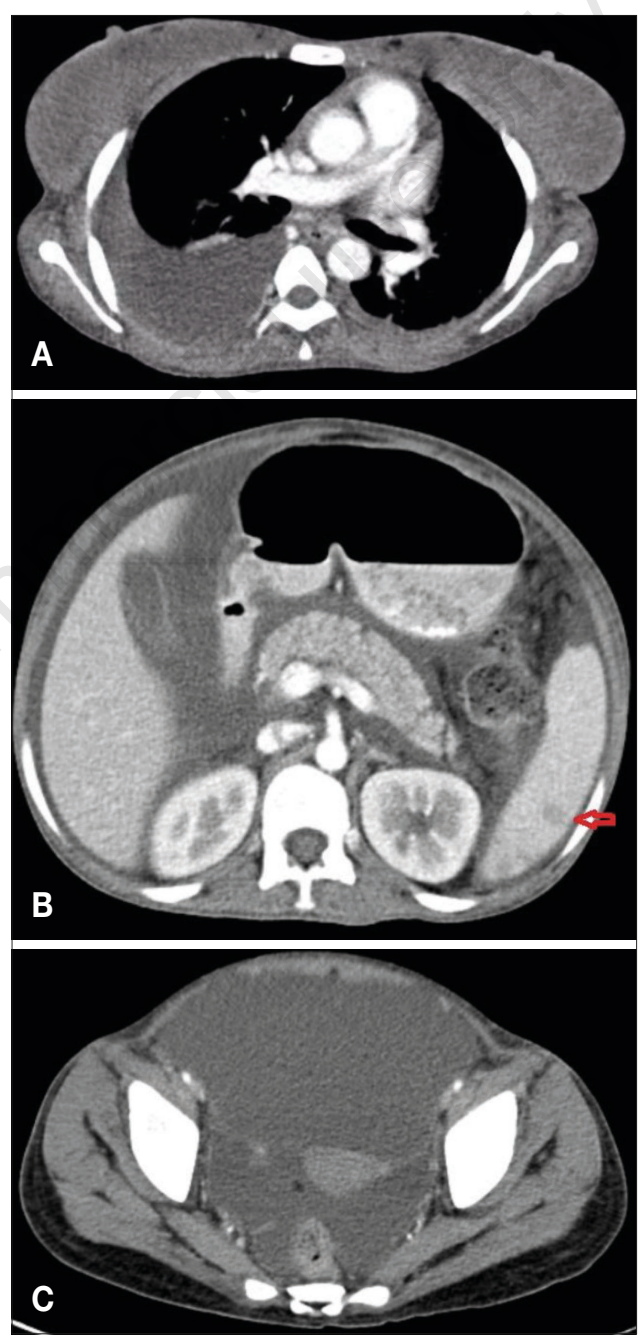

Figure 1 - A) Contrast enhanced computed tomography (CECT) chest showing moderate right and minimal left sided pleural effusion; B) CECT abdomen showing ascites with multiple splenic infarcts (arrow); C) CECT pelvis showing free fluid with normal adnexa. 
ditional immunosuppressant, $500 \mathrm{mg}$ of intravenous cyclophosphamide (CYC) every two weekly for a total of six doses. Repeat ultrasound done after two doses of CYC showed resolution of the ascites. A repeat CA-125 level at this time was $290 \mathrm{U} / \mathrm{mL}$, much lower than the initial level. Steroid was tapered gradually and she was initiated on azathioprine after completion of the CYC course. Oral anticoagulation was also added for splenic infarction to maintain INR between 2-3.

\section{DISCUSSION}

Meigs' syndrome is defined as the presence of ascites, pleural effusion and benign ovarian fibroma that resolves after surgical removal of the tumor. Pseudo-Meigs' syndrome is characterized by ascites and pleural effusion secondary to any other abdominal or pelvic malignancy. PPMS is defined as the presence of ascites, pleural effusion and raised CA-125 levels in a SLE patient, with no evidence of any abdominal or pelvic tumor.

The exact mechanism of pathogenesis is probably yet to be ascertained since the syndrome is uncommon and under-reported. It is hypothesized to be due to inflammatory pathology preferentially involving the serosa. An exaggerated inflammatory reaction leads to lympho-aggregation of plasma cells, deposition of immune complexes and vasculitis of the peritoneal vessels (11). Raised Interleukin-1b, IFN-gamma and VEGF have been described with this condition. The finding of raised serum ferritin and raised IL-6 levels in the ascitic fluid also contribute to the inflammatory theory of pathogenesis of PPMS $(12,13)$. Serum ferritin level in the present case was also slightly elevated although the patient had iron deficiency anemia. The ascites in PPMS is low SAAG ascites, as present in this case and in all previously reported cases. The pleural effusion, meanwhile, develops by mechanical passive transfer of ascitic fluid through diaphragmatic apertures, intracellular gaps or across lymphatic vessels by communication between the thorax and peritoneal cavity.
CA-125 is a commonly used tumor marker but lacks sensitivity and specificity for diagnosis of ovarian malignancy. It is not expressed in the tumor cells and can be raised in other conditions like SLE, nephrotic syndrome, interstitial lung disease and tuberculosis. There was no evidence of interstitial lung disease in our case and the raised CA-125 level was secondary to peritoneal inflammation. In inflammatory conditions, CA-125 secretion is increased from the mesovarium and omentum (14). Raised inflammatory cytokines like IL-1b and interferon-gamma increase CA-125 expression in the peritoneum. The average CA-125 levels among the reported cases of PPMS was $527 \mathrm{IU} / \mathrm{ml}$. Levels of CA125 have been shown to mirror the disease activity and resolution of the disease has shown a fall in CA-125 levels (15).

Pericardial effusion is also seen in PPMS. Out of 9 reported cases, 6 had pericardial effusion too. Even in our case there was mild pericardial effusion which resolved after treatment. ITP along with PPMS was previously reported only by Bes et al., and in the present case, too, there was secondary thrombocytopenia (8). Renal involvement in PPMS is not usually seen. Schmitt et al., did renal biopsy in their patient, which showed immune mesangial deposits (4). Lee et al., described 2 cases of PPMS, the first case had acute kidney injury and the second was a diagnosed case of lupus nephritis (9). Our patient had non-nephrotic range proteinuria with normal renal function tests. We did a renal biopsy which showed class II lupus nephritis. Similarly, APS is not commonly seen in PPMS. Antiphospholipid antibodies (aPL) were present in only two cases of PPMS described so far (Table I). Moreover, the presence of splenic infarcts in APS is a rare phenomenon and is generally associated with thrombosis of large intra-abdominal vessels (16). Here, splenic infarction was not associated with occlusion of any large vessel. This wide array of systemic manifestations in a newly diagnosed lupus patient makes our case unique.

It is important to note that PPMS is a diagnosis of exclusion. Other etiologies of as- 
Table I - Clinical profile of PPMS patients.

\begin{tabular}{|c|c|c|c|c|c|c|c|c|}
\hline Article & $\begin{array}{l}\text { Prior } \\
\text { SLE }\end{array}$ & $\begin{array}{l}\text { Pericardial } \\
\text { effusion }\end{array}$ & $\begin{array}{l}\text { Lupus } \\
\text { nephritis }\end{array}$ & ITP & APLA & $\begin{array}{c}\text { Initial } \\
\text { treatment }\end{array}$ & $\begin{array}{c}\text { Maintenance } \\
\text { treatment }\end{array}$ & $\begin{array}{l}\text { Time to } \\
\text { remission }\end{array}$ \\
\hline Tjalma (3) & Yes & No & No & No & No & Steroid, AZA & - & \\
\hline Schmitt et al. (4) & No & No & Yes & No & Yes & $\begin{array}{c}\text { Steroid, MMF, } \\
\text { HCQ }\end{array}$ & - & NA \\
\hline Ural et al. (5) & No & No & No & No & No & Steroid, $\mathrm{HCQ}$ & - & Eight weeks \\
\hline Bes and Soy(6) & No & Yes & No & No & No & Steroid & $\mathrm{HCQ}$ & Four weeks \\
\hline Dalvi et al. (7) & Yes & Yes & No & No & No & Steroid & MMF & NA \\
\hline Bes et al. (8) & No & Yes & No & Yes & No & Steroid, CYC & AZA & NA \\
\hline $\begin{array}{l}\text { Lee et al. (9) } \\
\text { ( } 2 \text { cases) }\end{array}$ & $\begin{array}{l}\text { No } \\
\text { Yes }\end{array}$ & $\begin{array}{l}\text { Yes } \\
\text { Yes }\end{array}$ & $\begin{array}{l}\text { No } \\
\text { Yes }\end{array}$ & $\begin{array}{l}\text { No } \\
\text { No }\end{array}$ & $\begin{array}{l}\text { Yes } \\
\text { No }\end{array}$ & $\begin{array}{c}\text { IV MP } \\
\text { IV MP, CYC }\end{array}$ & $\begin{array}{c}\text { Steroid, HCQ } \\
\text { MMF }\end{array}$ & $\begin{array}{c}\text { Four weeks } \\
\text { NA }\end{array}$ \\
\hline McVorran et al. (10) & Yes & Yes & No & No & No & IV MP & NA & NA \\
\hline Current case & No & Yes & Yes & Yes & Yes & $\begin{array}{c}\text { Steroid, CYC, } \\
\text { HCQ }\end{array}$ & $\mathrm{AZA}, \mathrm{HCQ}$ & Eight weeks \\
\hline
\end{tabular}

IV MP, intravenous methylprednisolone; CYC, cyclophosphamide; AZA, azathioprine; HCQ, hydroxychloroquine; MMF, mycophenolate mofetil; NA, not available.

cites such as nephrotic syndrome, proteinlosing enteropathy, constrictive pericarditis, Budd Chiari syndrome, infective and carcinomatous peritonitis must be ruled out before attributing it to the disease per se. Our patient had only non-nephrotic range proteinuria and there was no cardiac dysfunction. Other possible causes of ascites were ruled out by relevant investigations. Since PPMS is an inflammatory process, it is treated with immunosuppressants. Steroids are considered the cornerstone of treatment for PPMS and all patients reported so far received either oral or intravenous pulse steroid therapy. Some of them needed other immunosuppressants such as mycophenolate mofetil (3 cases), azathioprine ( 2 cases), cyclophosphamide ( 2 cases) and hydroxychloroquine (4 cases). Rituximab and Belimumab can be of potential use in the future. We chose CYC over other immunosuppressants because of its affordability and because patient had completed her family. However, CYC should be avoided in childbearing age due to the risk of gonadal toxicity.

\section{CONCLUSIONS}

PPMS is a rare diagnosis and could be the initial manifestation of SLE. Awareness of this entity among clinicians is crucial for early recognition and treatment. Effective treatment is available in form of immunosuppressants. We suggest that CA-125 levels be included in the work-up of SLE patients with ascites.

\section{REFERENCES}

1. Weinstein PJ, Noyer CM. Rapid onset of massive ascites as the initial presentation of systemic lupus erythematosus. Am J Gastroenterol. 2000; 95: 302-3.

2. Prasad S, Abujam B, Lawrence A, Aggarwal A. Massive ascites as a presenting feature of lupus. Int J Rheum Dis. 2012; 15: e15-6.

3. Tjalma WA. Ascites, pleural effusion, and CA 125 elevation in an SLE patient, either a Tjalma syndrome or, due to the migrated Filshie clips, a pseudo-Meigs syndrome. Gynecol Oncol. 2005; 97: 288-91.

4. Schmitt R, Weichert W, Schneider W, et al. Pseudo-pseudo Meigs' syndrome. Lancet. 2005; 366: 1672.

5. Ural UM, Kiliç A, Güngör T, et al. Tjalma's or pseudo-pseudo-Meigs' syndrome: a case report. Clin Exp Dermatol. 2008; 33: 363-64.

6. Bes C, Soy M. Pseudo-pseudo Meigs syndrome developed under the leflunomide therapy. Rheumatol Int. 2011; 31: 521-3.

7. Dalvi SR, Yildirim R, Santoriello R, Belmont HM. Pseudo-pseudo Meigs' syndrome in a patient with systemic lupus erythematosus. Lupus. 2012; 21: 1463-66.

8. Bes C, Dağlı Ü, Memedoğlu P, Soy M. A rare form of SLE: pseudo-pseudo meigs syndrome and hydrocephalus. Rheumatol Int. 2013; 33: 2175-76. 
9. Lee SY, Lee SW, Chung WT. Severe inflammation may be caused by hyperferritinemia of pseudo-pseudo Meigs' syndrome in lupus patients: two case reports and a literature review. Clin Rheumatol. 2013; 32: 1823-26.

10. McVorran S, Song J, Pochineni V, AbrudescuOpran A. Systemic lupus erythematosus presenting with massive ascites: a case of pseudopseudo meigs syndrome. Case Rep Rheumatol. 2016; 2016: 8701763 .

11. Pott Júnior H, Amate Neto A, Teixeira MA, Provenza JR. Ascites due to lupus peritonitis: a rare form of onset of systemic lupus erythematosus. Rev Bras Reumatol. 2012; 52: 116-9.

12. Lim MK, Lee CK, Ju YS, et al. Serum ferritin as a serologic marker of activity in systemic lupus erythematosus. Rheumatol Int. 2001; 20: 89-93.
13. Watanabe R, Fujii H, Kamogawa Y, et al. Chronic lupus peritonitis is characterized by the ascites with a large content of interleukin-6. Tohoku J Exp Med. 2015; 235: 289-94

14. Zeimet AG, Marth C, Offner FA, et al. Human peritoneal mesothelial cells are more potent than ovarian cancer cells in producing tumor marker CA-125. Gynecol Oncol. 1996; 62: 384-9.

15. Yang Z, Liang Y, Li C, Zhong R. Serum CA125 elevation is independently associated with serositis in SLE patients. Clin Exp Rheumatol. 2012; 30: 93-8.

16. Uthman I, Khamashta M. The abdominal manifestations of the antiphospholipid syndrome. Rheumatology (Oxford). 2007; 46: 1641-7. 